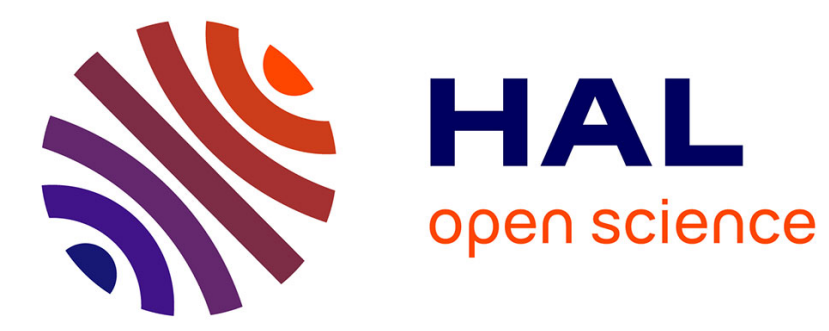

\title{
Experimental Study of Photon-Phonon Interactions in an Explosive by Laser Probe Mass Spectrography
}

\author{
J. Eloy, A. Delpuech
}

\section{To cite this version:}

J. Eloy, A. Delpuech. Experimental Study of Photon-Phonon Interactions in an Explosive by Laser Probe Mass Spectrography. Journal de Physique IV Proceedings, 1995, 05 (C4), pp.C4-379-C4-382. 10.1051/jp4:1995430 . jpa-00253735

\section{HAL Id: jpa-00253735 https://hal.science/jpa-00253735}

Submitted on 1 Jan 1995

HAL is a multi-disciplinary open access archive for the deposit and dissemination of scientific research documents, whether they are published or not. The documents may come from teaching and research institutions in France or abroad, or from public or private research centers.
L'archive ouverte pluridisciplinaire HAL, est destinée au dépôt et à la diffusion de documents scientifiques de niveau recherche, publiés ou non, émanant des établissements d'enseignement et de recherche français ou étrangers, des laboratoires publics ou privés. 


\title{
Experimental Study of Photon-Phonon Interactions in an Explosive by Laser Probe Mass Spectrography
}

J.F. Eloy and A. Delpuech

Commissariat à l'Energie Atomique

\begin{abstract}
We have shown in a series of previous papers the part of the molecular electronic structure played in the decomposition process of an explosive submitted to a shock wave. This part is important especially as regards energy transfer properties.

This work is intented to investigate the process of these transfers by the study of photon-phonon interactions in this type of material. The experimental technique used for this purpose is laser probe mass spectrography. The first tested explosives are RDX and HMX studied in the shape of single crystals.
\end{abstract}

\section{INTRODUCTION}

In previous discussions, we have stated that the conditions for the birth of detonating regime were directly dependent on the properties of energy transfer between molecules. In the proposed model, these properties take account of preferable nitrated groups. These initiation conditions suppose both mechanisms of molecular excitation under shock, similar to those observed under radiation, and de-excitation processes by means of lattice's phonons.

In order to confirm and analyse the fundamental behaviour of the $\mathrm{NO}_{2}$ groups involved in such mechanism, we intended to study the photon-phonon interactions in the case of nitrated secondary explosives. The primary difficulty was in the choice of an experimental technique which allowed investigation of both decomposition fragments and their mechanism of generation. We considered the time of flight (T.O.F.) laser probe mass spectrograph (L.P.M.S.) was the one appropriate technique to reach this dual purpose.

I present here the results of the RDX and HMX study (in single crystal form) by the T.O.F. laser probe mass spectrograph.

The results are analysed with regard to a non-linear approach of the laser explosive interaction. 


\section{INSTRUMENTATION AND METHODS}

The vaporization and ionization of the explosive single crystal are induced by laser beam bombardment of one crystal face. The (Nd/YAG) laser head used delivers a tripled frequency $(\lambda=0,355 \mu \mathrm{m})$ of a TEM $\mathrm{THO}_{00}$ laser beam. The total energy of the laser impulse is between 10 and $30 \mu \mathrm{J}$ and focused on a surface of about $400 \mu \mathrm{m}^{2}$ with gaussian spatiotemporal profiles. The laser time duration is $3-4 \mathrm{~ns}$ and the shot repetition rate is $1 \mathrm{~Hz}$.

The so-created laser micro-plasma is released in an equipotential expansion box without electric and magnetic fields. The positive ionic species are then extracted and accelerated by an electrostatic field corresponding to a difference of potential of $8 \mathrm{kV}$. These ions are analysed by a spatio-temporal mass-separator combining both magnetic field action and time of flight separation. They are detected by an electro-optic panoramic device and their masses identified by time of flight measurements.

The instrument is equipped with a sample viewing system witch provides a high power observations ( $\mathrm{G}: 300-420 \mathrm{X})$.

\section{3. $\underline{\text { RESULTS }}$}

In brief, the study of the RDX and HMX single crystals behaviour under laser bombardment reveals the emission of three types of mass spectra. Two types correspond to "classic" mass spectra of organic compound fragmentation by laser pyrolysis. One type (characterised by very energetic ionic species, very high ionized plasma and very high electronic density and temperature) is distinctive of the explosive. Its appearance is likely due to the "explosive" feature of this material.

interaction.

The study of the crystalline faces considers a mechanism of non-linear

The study of the crater shapes by optical microscopy (binocular) reveals that the laser beam effect induces physical transformations (appearance of a "white zone" area) of the crystal around the distances between 30 to $80 \mu \mathrm{m}$. The observations of the craters by scanning electron microscopy (SEM) reveals : of structure collapse,

- the formation of cracks a long way from the crater $(>50 \mu \mathrm{m})$ as a consequence

- a truncated shape of these craters witch results from a sudden vaporisation initiated "in volume".

Now, we intend to consider the physical phenomena wich can explain at once this non-linear effect and "white zone" area creation $(\phi=30-80 \mu \mathrm{m})$ around the crater. 


\section{PROPOSAL OF A MODEL FOR THE LASER EXPLOSIVE INTERACTION}

Taking only the phonons (created by the laser beam in surface and in volume) into account is insufficient to explain our experimental results. The energy carried by the phonons is insufficient to generate the observed craterization effect ; and the appearance of the "white zone" suppose a speed of propagation for the particles twice the speed of phonons. In fact, a non-negligible probability of interaction exists between photons and phonons in the crystalline medium. These interactions generate a process of "chain reaction". Each centre of interaction becomes the spot where an energy liberation can produce dislocations and energetic chain reactions by bond breakings. In this case, the laser decomposition is initiated in volume (and not in surface) in opposition to the general case of organic and metallic materials.

The coupling of the vibration waves (or phonons) of the lattice with an electromagnetic wave causes a polarization wave (or polariton) to appear. This P-wave propagates itself in the material and induces the application of a force on the bond dipole. This force will be all the stronger as the dipolar moment is strong. In the case of RDX and HMX, the N-NO 2 groups will be the more strongly activated.

Three facts are in keeping with the model proposed :

- the initiation of the laser decomposition by such a process leads to a large proportion of $\mathrm{NO}^{+}$ions. Our mass spectra reveal systematically this effect,

- the middle extinction curve of polarization wave ( $\mathrm{P}$-wave) is compatible with the size of the sensitive "white zone",

- the observation of an interaction especially efficient with the crystalline axis which offers a higher density of nitrated bonds.

\section{CONCLUSION}

The first results of this work is to confirm the original contribution of the laser probe mass spectrograph for the study of photon-explosive interactions mechanism.

The results obtained as a whole permit the conclusion that the behaviour of this explosive material is different in regard to all the organic products previously studied with this technique. We proved that this material is a medium which induces non-linear phenomena.

Our experimental results also demonstrate an appropriate decomposition model by taking non-linear effects into account. This approach is supported by three kinds of processes :

- phonons generations by photon absorption,

- photon and phonon propagation is the volume of material,

- creation of hot centers by polarization wave ( $P$-wave) interaction with the $\mathrm{N}-\mathrm{NO}_{2}$ dipoles.

The fundamental part played by the nitrated bonds in the initiation mechanism of the explosive decomposition is like that confirmed. 


\section{REFERENCES}

[1] S. DUFORT, A. DELPUECH

The $8^{\text {th }}$ Symposium on Detonation -

ALBUQUERQUE (USA) - 1985

[2] A. CHAME, J.F. ELOY

Scanning Electron Microsc. - 1983/II p. 841 - 851

[3] J.F. ELOY, A. DELPUCEH

APS Topical Conference - Shock Waves in Condensed Matter MONTEREY (USA) - 1987 